Article

\title{
More Than Just Concrete: Acoustically Efficient Porous Concrete with Different Aggregate Shape and Gradation
}

\author{
Louena Shtrepi $^{1, *}{ }^{\oplus}$, Arianna Astolfi $\left.{ }^{1}{ }^{(}\right)$, Elena Badino ${ }^{1} \oplus$, Giovanni Volpatti ${ }^{2}$ and Davide Zampini ${ }^{3}$ \\ 1 Department of Energy (DENERG), Corso Duca degli Abruzzi 24, Politecnico di Torino, 10129 Torino, Italy; \\ arianna.astolfi@polito.it (A.A.); elena.badino@polito.it (E.B.) \\ 2 CEMEX Innovation Holding AG—Brügg Branch, Römerstrasse 13, 2555 Brügg, Switzerland; \\ giovanni.volpatti@cemex.com \\ 3 CEMEX Innovation Holding AG, General-Guisan-Strasse 6, 6300 Zug, Switzerland; \\ davide.zampini@cemex.com \\ * Correspondence: louena.shtrepi@polito.it
}

check for updates

Citation: Shtrepi, L.; Astolfi, A.; Badino, E.; Volpatti, G.; Zampini, D. More Than Just Concrete:

Acoustically Efficient Porous

Concrete with Different Aggregate Shape and Gradation. Appl. Sci. 2021, 11, 4835. https://doi.org/10.3390/ app11114835

Academic Editors: Edoardo Piana,

Paolo Bonfiglio and

Monika Rychtarikova

Received: 27 April 2021

Accepted: 21 May 2021

Published: 25 May 2021

Publisher's Note: MDPI stays neutral with regard to jurisdictional claims in published maps and institutional affiliations.

Copyright: (C) 2021 by the authors Licensee MDPI, Basel, Switzerland. This article is an open access article distributed under the terms and conditions of the Creative Commons Attribution (CC BY) license (https:/ creativecommons.org/licenses/by/ $4.0 /)$.
Featured Application: The use of acoustically efficient porous concrete with weighted absorption coefficients $\left(\alpha_{w}\right)$ in the range of 0.30 to 0.75 for noise control in outdoor and indoor applications.

\begin{abstract}
The interest in the use of resistant acoustic materials has put further attention on the use of porous concrete in the building industry. This work investigates the acoustic properties of four different mix designs of porous concrete obtained with two types of aggregates, that is, normal weight and lightweight aggregates. The assessment of the sound-absorbing performances has been conducted in the small-scale reverberation room (SSRR) at Politecnico di Torino (Italy), in agreement with the procedure indicated in the ISO 354 Standard. For each concrete type, three panel thicknesses, i.e., $20 \mathrm{~mm}, 40 \mathrm{~mm}$, and $60 \mathrm{~mm}$, were tested. Moreover, different mounting conditions were investigated, considering the combination of single panels in multiple layers, adding an air gap between the panel and the backing, and inserting a layer of rock wool in the air gap itself. The results show weighted absorption coefficients $\left(\alpha_{w}\right)$ in the range of 0.30 to 0.75 depending on the thickness and mounting conditions. These encouraging values make these materials useful for efficient practical applications in indoor and outdoor environments.
\end{abstract}

Keywords: acoustics; acoustic measurements; sound absorption coefficient; cement-based materials; building materials; pervious concrete; acoustic concrete

\section{Introduction}

The implementation of noise control strategies in outdoor environments is a challenging task for several professionals, and an increasing number of studies highlight the importance of the architectural design on urban noise mitigation in canyon streets $[1,2]$ squares [3] and inner yards [4]. A detailed overview of the acoustic strategies used for the building envelope design in order to improve the urban acoustic environment is given in [5]. These studies have pointed out the need for sound-absorbing and -scattering materials suitable for outdoor environments. Moreover, several indoor spaces such as airports, train stations, schools, etc. are characterized by requirements similar to those of outdoor spaces regarding highly durable and resistant acoustic materials. Therefore, this work aims to investigate the sound absorbing properties of porous concrete of different mix designs, thicknesses and mounting conditions, as this material results suitable for outdoor and indoor applications. Compared to other porous sound absorbers, porous concrete has the capability to withstand the atmospheric elements, and therefore it is suitable for applications in outdoor and indoor environments when resistance, low deformability, and high durability are required. 
Porous absorbers are the most widespread type of sound absorbers. According to their microstructure, porous absorbers can be further classified into granular, cellular, and fibrous [6,7]. The most fundamental properties of porous materials influencing their sound absorbing properties are flow resistivity and porosity and second, pore shape factor and tortuosity [7].

Conventional concrete is generally characterized by poor sound-absorbing properties, as the prevailing phenomena occurring are sound reflections. In general, normal concrete has an absorption coefficient value of $0.05-0.10$ [8]. However, porous concrete has the capability to work as a porous sound-absorbing material as it is characterized by high porosity, i.e., open pore structure on its surface and an interconnected network of pores. It is also known as pervious, gap-graded, permeable, or enhanced porosity concrete [9] and is currently widely used in urban environments as paving material to support environmentally sustainable rainwater management [10]. It has been also exploited for its acoustic absorbing properties in traffic noise barriers and railway noise reduction [11-13]. Pervious concrete mainly consists of normal Portland cement, coarse aggregates (aggregate dimension greater than $5 \mathrm{~mm}$ ), and water, which generate a void content that generally ranges from $15 \%$ to $35 \%$ [10,14-16]. Pervious concrete acoustic panels belong to the class of granular sound absorbers with pores created by the presence solid aggregates which are bonded together by a cementitious binder. The key factor to allow sound absorption to occur is the accurate definition of the quantity of binder to ensure that there is enough binder to keep the aggregate together without clogging the pore network and still allow for an appropriate resistance for its use and handling. Overall, the sound-absorbing properties of granular materials tend to be uneven in frequency and to be characterized by peaks [17].

Different strategies have been proposed with the intent to improve the sound absorbing properties, i.e., with the aim to enhance the rate and the evenness of the sound absorption provided by altering the microstructural properties of the pervious concrete. Note that these strategies applied to the mix design aim to vary the fundamental properties, i.e., flow resistivity, porosity, pore shape factor, and tortuosity, which control the absorbing performance. Indeed, the sound absorption properties of porous concrete are strictly related to the void ratio of the concrete. Therefore, it is important to adequately control the void ratio and aggregate type, which influence tortuosity and flow resistivity [18], pore size, and pore aperture size, which are used to control porosity [8]. A higher void ratio leads to higher and wider peak values in acoustic absorption coefficients, resulting in a shift of the peak of the coefficient towards the higher frequencies $[12,19,20]$.

The effect on sound absorption of the aggregate size and different aggregate types by blending or combining them in multiple layers has been studied in [11,13,21,22]. Aggregate size can be used to control the pore dimensions, as the median pore size increases for increasing aggregate size $[19,21]$. With respect to aggregate size, it has been observed that most previous studies endorse the use of aggregate with dimensions in the range 1 to $10 \mathrm{~mm}$ [11,21,22], as smaller aggregates would clog the pores, thus reducing porosity, and bigger ones, despite increasing the pore volume, would reduce the tortuosity of the pore network. When considering the use of different aggregate types such as lightweight and normal-weight aggregates, the study in [22] suggests that lightweight aggregates can absorb cement paste from micropores on the surface of the aggregates. As a result, for an equal absolute volume ratio of aggregates, smaller size lightweight aggregates result in slightly higher sound absorbing performance, as they have a larger total surface area compared to bigger ones, and therefore the cement paste covering the aggregates can be better absorbed when smaller aggregates are used and result in higher void ratio values with respect to normal weight aggregates [22]. Other studies have investigated the use of different materials as aggregates, such as crumb rubber, cenospheres, and recycled aggregates [12,13,23-25]. The possibility of blending aggregates with different size in the concrete matrix has been studied in $[19,21]$, highlighting that, as a general rule, aggregate size should be selected in order to ensure that smaller aggregates do not enter the pores created by the bigger ones. Porous concretes with blends of aggregates of different materials 
have been tested in [11], where expanded perlite aggregates were replaced by different percentages of slag, evidencing a nonlinear impact on the sound absorption performance of the panels. Concrete samples featuring aggregates of different dimensions or material have been combined into layers in $[11,13,22]$, evidencing the coupling two layers of concrete with the external one featuring aggregates with lower bulk densities or bigger pores sizes compared to the back layer lead to increased sound absorbing performances.

Slight differences in sound absorption have been reported regarding the shape of the aggregates; for instance, this was shown in [22], i.e., which has compared round shape (lightweight) and irregular shape (normal weight) aggregates with similar gradation.

Moreover, as for all the acoustic porous materials, the thickness of the porous layer also results as important for the acoustic absorption coefficient spectra. The principal maximum peak of the absorption coefficient is displaced to lower frequencies when the thickness increases $[13,18,21]$. However, there is a threshold regarding the thickness of granular materials above which the absorption does not increase further [7]. Table A1 (Appendix A) briefly summarizes the details and the main findings of previous research investigating the effects of design factors on the sound absorption coefficient of porous concrete. The studies which analyzed different aggregate size, material and shape, and on panel thickness have been clustered evidencing if and the extent to which such variable was found to have an influence on the sound absorbing properties of the panels.

Recent reviews on the strategies that have been proposed to enhance the sound absorbing performances of concrete have been presented in $[17,26]$. However, these reviews highlight the fact that further research is required to provide larger datasets to refine and produce better estimation of the sound absorption of concrete materials.

Therefore, the following study aims to provide further experimental data on the investigation of some design guidelines for sound absorbing concrete emerging from the past research regarding the aggregate shape and size. The present study investigates, through a systematic research approach, the effects of concrete mix design (four different conditions), sample thickness (three different conditions), and mounting conditions (three different conditions) on the absorption properties of porous concrete tested in a small-scale reverberation room (SSRR). Therefore, the main aim of this study is to define the sample configuration that could lead to an increase of the sound absorption properties of concrete panels. More than 30 different combinations of the aforementioned variables have been considered. Note that besides providing a useful database of measured data in addition to previous research, this work presents novel configurations, that is, mounting conditions with an air gap and combination in multiple layers with other porous materials. To the authors' knowledge, this has not been studied in previous literature.

This work aims to increase awareness on the porous concrete properties among several professionals such as architect, designers, acousticians, policy-makers, etc. that deal with noise control strategies in outdoor and indoor environments.

\section{Materials and Methods}

The research has been organized through the following steps:

(1) Selection of different concrete mix design and preparation of samples for the measurements.

(2) Selection of different mounting methods.

(3) Measurement of the frequency-dependent sound absorption $\alpha$ s in the SSRR.

(4) Computation of the weighted sound absorption coefficients as single index $\alpha_{w}$ and comparisons.

\subsection{Tested Concretes}

Information regarding the porous concrete types, identified with the letters $\mathrm{A}, \mathrm{B}$, $\mathrm{C}$, and $\mathrm{D}$, are summarized in Table 1 . The following parameters are reported: aggregate size (according to EN 933-2:2020 [27]), aggregate particle density (according to EN 1097-6:2013 [28]), void ratio (according to ASTM C1754/C1754M [29]), flexural strength 
(according to EN 12390-5:2019 [30]), previous concrete density (according to ASTM C1754/ C1754M [29]), and water permeability (according to ASTM D2434-19 [31]). Two different types of aggregates have been used in the mix design: normal weight and lightweight. The normal weight aggregates have been used in concrete type A and have an irregular shape with an average dimension of 4-8 $\mathrm{mm}$, while the lightweight aggregates have an almost perfect round shape, i.e., spherical, with different dimensions ranging between 4 and $8 \mathrm{~mm}, 2$ and $4 \mathrm{~mm}$, and 0.5 and $1 \mathrm{~mm}$ for concretes B, C, and D, respectively.

Table 1. Four mix design of porous concrete characteristics with respect to: aggregate size, aggregate particle density, void ratio, flexural strength, previous concrete density, and water permeability.

\begin{tabular}{|c|c|c|c|c|c|c|c|}
\hline Concretes & $\begin{array}{l}\text { Aggregate } \\
\text { Typology }\end{array}$ & $\begin{array}{c}\text { Aggregate } \\
\text { Size } \\
{[\mathrm{mm}]}\end{array}$ & $\begin{array}{c}\text { Aggregate } \\
\text { Particle } \\
\text { Density }\left[\mathrm{kg} / \mathrm{m}^{3}\right]\end{array}$ & $\begin{array}{c}\text { Void } \\
\text { Ratio } \\
{[\%]}\end{array}$ & $\begin{array}{c}\text { Flexural } \\
\text { Strength } \\
\text { [MPa] }\end{array}$ & $\begin{array}{c}\text { Pervious } \\
\text { Concrete } \\
\text { Density }\left[\mathrm{kg} / \mathrm{m}^{3}\right]\end{array}$ & $\begin{array}{c}\text { Water } \\
\text { Permeability } \\
{[\mathrm{mm} / \mathrm{s}]}\end{array}$ \\
\hline A & $\begin{array}{l}\text { crushed } \\
\text { normal weight } \\
\text { aggregates } \\
\text { round }\end{array}$ & $4-8$ & $2650 \pm 30$ & $25 \pm 2$ & $3.5 \pm 0.5$ & $1955 \pm 20$ & $9.5 \pm 1.1$ \\
\hline B & $\begin{array}{l}\text { lightweight } \\
\text { aggregates } \\
\text { round }\end{array}$ & $4-8$ & $905 \pm 85$ & $25 \pm 3$ & $1.5 \pm 0.3$ & $932 \pm 35$ & $10.9 \pm 1.7$ \\
\hline $\mathrm{C}$ & $\begin{array}{l}\text { lightweight } \\
\text { aggregates } \\
\text { round }\end{array}$ & $2-4$ & $325 \pm 35$ & $25 \pm 2$ & $1 \pm 0.2$ & $514 \pm 20$ & $7.4 \pm 0.9$ \\
\hline $\mathrm{D}$ & $\begin{array}{l}\text { lightweight } \\
\text { aggregates }\end{array}$ & $0.5-1$ & $510 \pm 70$ & $20 \pm 2$ & $0.5 \pm 0.1$ & $682 \pm 15$ & $3.6 \pm 0.5$ \\
\hline
\end{tabular}

Details of the aggregate shape can be visualized in Figure 1.
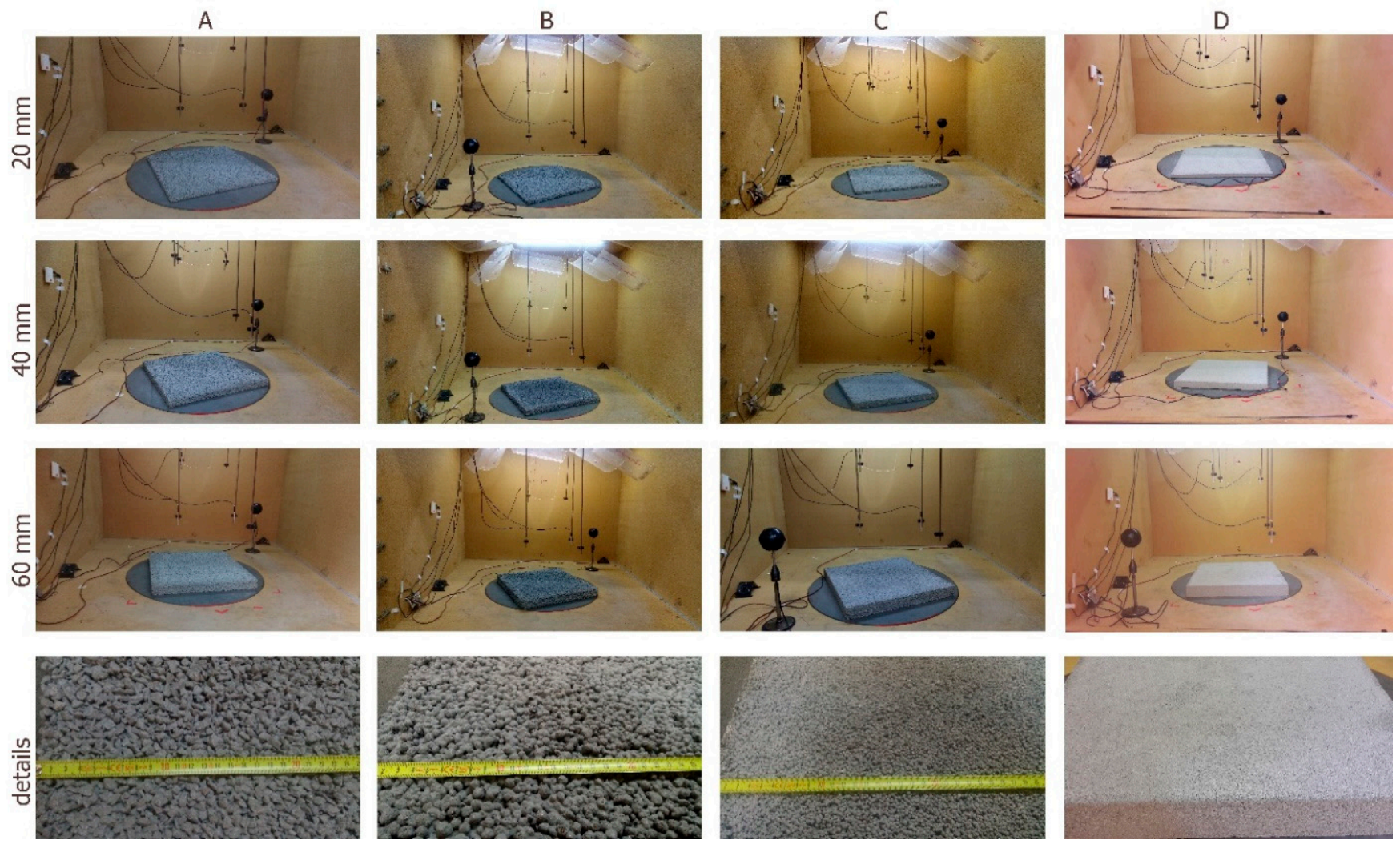

Figure 1. Sample (A): crushed normal weight aggregates 4-8 mm; Sample (B): round lightweight aggregates 4-8 mm; Sample (C): round lightweight aggregates 2-4 mm; Sample (D): round lightweight aggregates 0.5-1 mm. 
Concrete A differs significantly from the other three regarding the concrete density value, which is strongly affected by the higher values of the aggregate particle density. The four concretes present a similar void ratio. However, while this parameter is constant for concretes $\mathrm{A}, \mathrm{B}$, and $\mathrm{C}$, it decreases for concrete type $\mathrm{D}$, which features smaller aggregates. It can also be noticed that there is a decrease in the flexural strength for lower densities and smaller aggregate dimensions.

For each concrete, three different sample types have been manufactured with three different thicknesses, i.e., $20 \mathrm{~mm}, 40 \mathrm{~mm}$, and $60 \mathrm{~mm}$ (Figure 1); for each of them, three samples have been produced. The panels are square-shaped in plan with a side dimension of $60 \mathrm{~cm}$. Three different mounting conditions were tested for the samples with a thicknesses of 20 and $40 \mathrm{~mm}$, that is, coupling different samples in multiple layers (Figure 2), adding a $50 \mathrm{~mm}$ air gap between the sample and the room floor (Figure 3), and adding a layer of fibrous material (rock wool) in the air gap itself (Figure 4). The identification codes of the samples and mounting conditions have been summarized in Table 2 . The coupling of different samples in multiple layers has been performed only within the same concrete in order to compare their performance with single layers of the same thickness and investigate any anisotropy at the back surface of each layer. The multiple layer configuration is obtained by superimposing one panel to the other, with no joint or glue connecting them. This mounting solution could be practically useful when modular solutions are explored and would limit the need for different formwork thicknesses. The introduction of a rock wool layer in the air gap has been tested with sample D of $20 \mathrm{~mm}$ thickness only as it resulted in the highest sound absorption performances compared to the $20 \mathrm{~mm}$ samples of $\mathrm{A}, \mathrm{B}$, and C concretes. In this case, two thicknesses of the rock wool layer-30 and $50 \mathrm{~mm}$-have been introduced in the air gap.

A
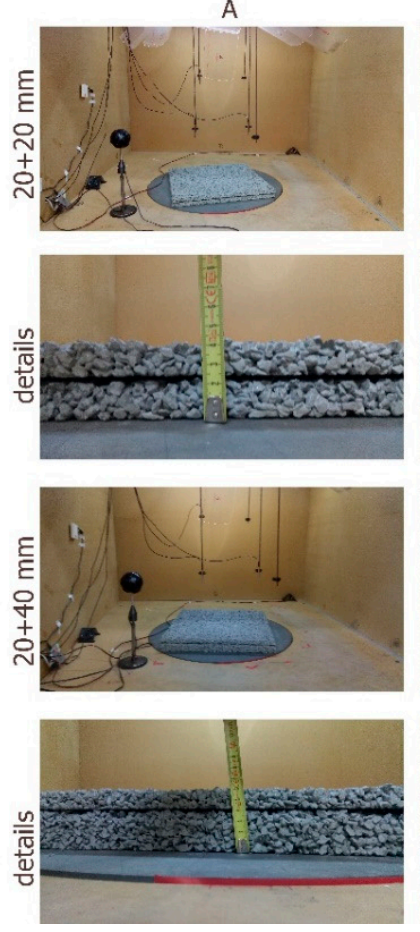

B
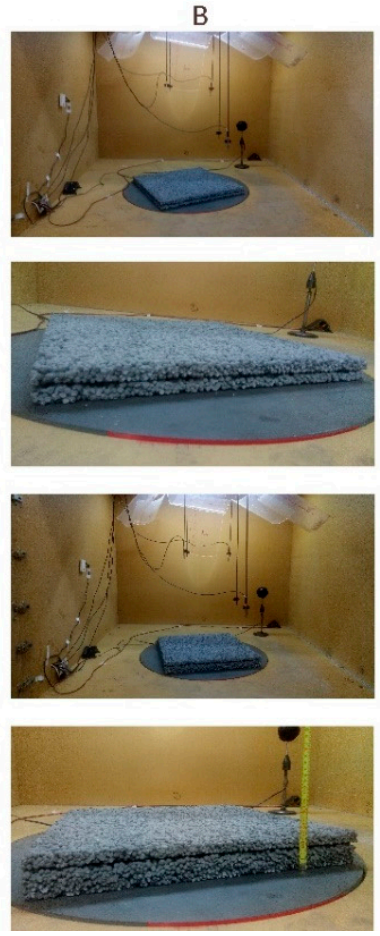

C
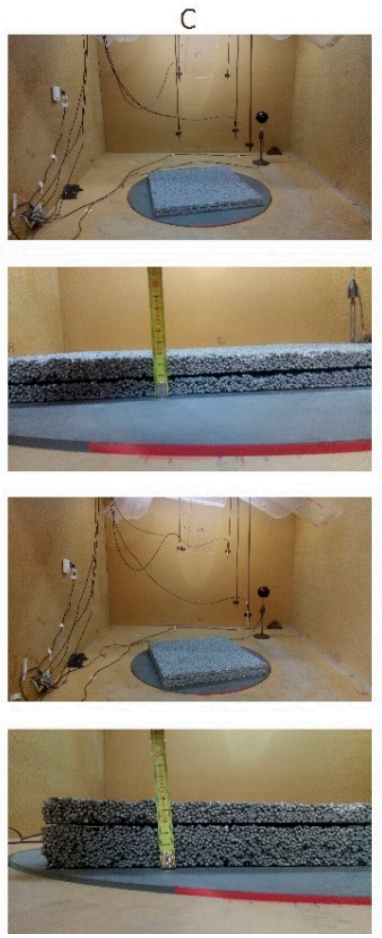

D
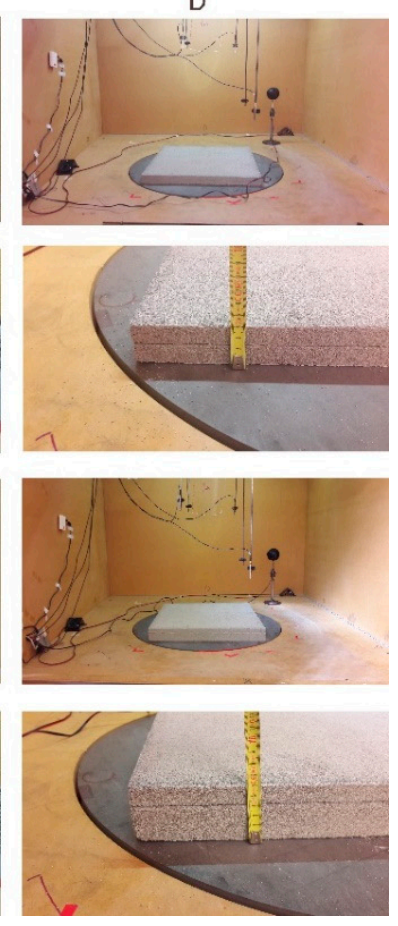

Figure 2. Multiple layers of $20+20 \mathrm{~mm}$ and $20+40 \mathrm{~mm}$. Sample (A): crushed normal weight aggregates 4-8 mm; Sample (B): round lightweight aggregates 4-8 $\mathrm{mm}$; Sample (C): round lightweight aggregates 2-4 mm; Sample (D): round lightweight aggregates $0.5-1 \mathrm{~mm}$. 
A
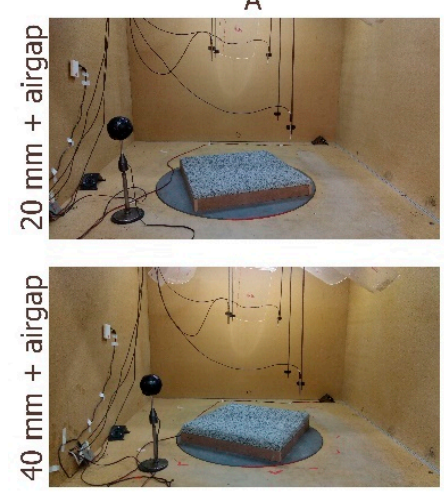

B
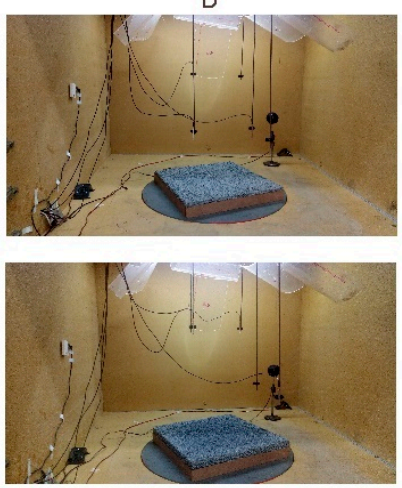

C


D
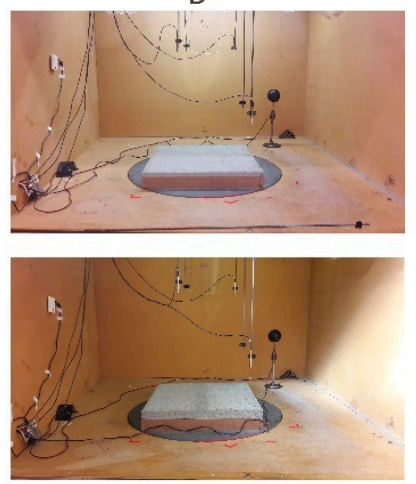

Figure 3. Mounting on $50 \mathrm{~mm}$ air gap. Sample (A): crushed normal weight aggregates 4-8 mm; Sample (B): round lightweight aggregates 4-8 mm; Sample (C): round lightweight aggregates 2-4 mm; Sample (D): round lightweight aggregates $0.5-1 \mathrm{~mm}$.
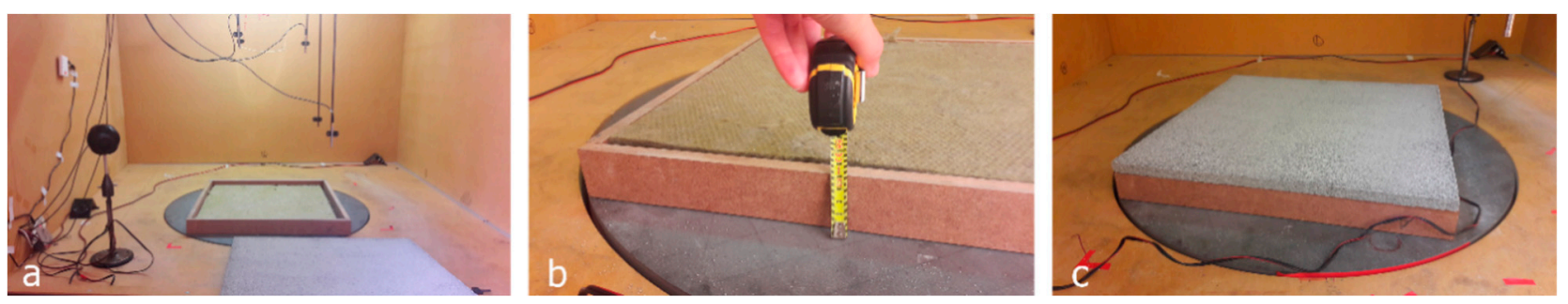

Figure 4. (a) $30 \mathrm{~mm}$ and (b) $50 \mathrm{~mm}$ rock wool filling $50 \mathrm{~mm}$ air gap. (c) Sample D of $20 \mathrm{~mm}$ over one of the two conditions.

Table 2. Summary of the tested samples and configurations of the porous concrete. Single layers have been tested in configurations of multiple layers, with air gap and with rock wool in the airgap (+tested and - untested configurations of single layers).

\begin{tabular}{|c|c|c|c|c|c|}
\hline \multirow{2}{*}{$\begin{array}{l}\text { Concrete } \\
\text { Type }\end{array}$} & \multirow{2}{*}{$\begin{array}{c}\text { Overall } \\
\text { Thickness [mm] }\end{array}$} & \multicolumn{2}{|c|}{ Layer Thickness [mm] } & \multirow{2}{*}{$\begin{array}{l}\text { Air Gap } \\
50 \mathrm{~mm}\end{array}$} & \multirow{2}{*}{$\begin{array}{c}\text { Rock Wool } \\
\text { Thickness [mm] }\end{array}$} \\
\hline & & Single Layer & Multiple Layers & & \\
\hline \multirow{3}{*}{ A } & 20 & 20 & & + & - \\
\hline & 40 & 40 & $20+20$ & + & - \\
\hline & 60 & 60 & $20+40$ & - & - \\
\hline \multirow{3}{*}{ B } & 20 & 20 & & + & - \\
\hline & 40 & 40 & $20+20$ & + & - \\
\hline & 60 & 60 & $20+40$ & - & - \\
\hline \multirow{3}{*}{$\mathrm{C}$} & 20 & 20 & & + & - \\
\hline & 40 & 40 & $20+20$ & + & - \\
\hline & 60 & 60 & $20+40$ & - & - \\
\hline \multirow{5}{*}{$\mathrm{D}$} & & & & & - \\
\hline & 20 & 20 & & + & 30 \\
\hline & & & & & 50 \\
\hline & 40 & 40 & $20+20$ & + & - \\
\hline & 60 & 60 & $20+40$ & - & - \\
\hline
\end{tabular}

The assessment of the sound absorbing performances has been conducted in the smallscale reverberation room (SSRR) of Politecnico di Torino (Italy), following the procedure indicated in the ISO 354 Standard [32]. The reliability of the measurement was tested with respect to reproducibility and repeatability, by repeating the measures three times on three different samples of the same typology and considering their arithmetic mean to describe the performances of each type. The sound absorbing properties are expressed as 1/3 octave 
band sound absorption coefficients $(\alpha)$ and also as weighted sound absorption coefficients $\left(\alpha_{w}\right)$ for an easier comparison.

\subsection{Sound Absorption Coefficient Measurements}

The small-scale reverberation room (Figures 1-4) is installed in the Applied Acoustics laboratory at DENERG (Department of Energy, Politecnico di Torino, Torino, Italy). The room has been primarily built for random-incidence scattering coefficient measurements according to ISO 17497-1 [33], but it is also suitable for measurement of sound absorption coefficient according to ISO 354 [32,34]. It is an oblique angled room with pairs of non-parallel walls with a volume of $2.86 \mathrm{~m}^{3}$ and a total area of $12.12 \mathrm{~m}^{2}$. A more detailed description of the room construction has been provided in Shtrepi and Prato [35].

The measurement procedure consists in using the integrated impulse response method [32] for simultaneous measurements on six different microphone positions in two conditions, i.e., with and without the sample inside the room. The measurement chain consists of six 1/4" BSWA Tech MPA451 microphones and ICP104 (BSWA Technology Co., Ltd., Beijing, China), two ITA High-Frequency Dodecahedron Loudspeakers with their specific ITA power amplifiers (ITA-RWTH, Aachen, Germany), and a sound card Roland Octa-Capture UA-1010 (Roland Corporation, Shizuoka, Japan). This setup allows to perform 12 measurements, which refer to the minimum number required by ISO 354:2003 [32]. The software used for the measurements, i.e., sound generation, recording, and signal processing, is MATLAB combined with the functions of the ITA-Toolbox (an opensource toolbox by RWTH-Aachen, Aachen, Germany) [36].

For each of the 12 measurements the reverberation time relative to a $20 \mathrm{~dB}$ decay, i.e., $\mathrm{T}_{20}$, is evaluated and used to estimate the $\mathrm{T}_{60}$, i.e., the reverberation time occurring for a $60 \mathrm{~dB}$ decay, as done in the full-scale reverberation room (FSRR) data processing. The data are spatially averaged with the ensemble averaging method in order to obtain the reverberation times $T_{1}$ and $T_{2}$, which are obtained without and with the sample inside the room, respectively. Equations (1) and (2) are applied to estimate the random-incidence absorption coefficient $\alpha_{s}$.

The difference between $T_{1}$ and $T_{2}$ measurements is used to calculate the variation of the equivalent sound absorption area $A_{T}\left[\mathrm{~m}^{2}\right]$ based on Sabine's theory:

$$
A_{T}=55.3 V\left(\frac{1}{c_{2} T_{2}}-\frac{1}{c_{1} T_{1}}\right)-4 V\left(m_{2}-m_{1}\right)
$$

where $T_{1}$ and $T_{2}[\mathrm{~s}]$ are the reverberation times of the empty reverberation room and of the reverberation room with the test specimen, respectively; $V\left[\mathrm{~m}^{3}\right]$ is the volume of the empty reverberation room; $c_{1}$ and $c_{2}[\mathrm{~m} / \mathrm{s}]$ are the propagation speed of sound in air in the room without and with the sample: $c_{1}=331+0.6 t_{1}, t_{1}\left[{ }^{\circ} \mathrm{C}\right]$ is the air temperature; and $m_{1}$ and $m_{2}$ $\left[\mathrm{m}^{-1}\right]$ is the power attenuation coefficient of the climatic conditions in the reverberation room without and with the sample (calculated according to ISO 9613-1 [37]).

The random-incidence absorption coefficient $\alpha_{s}$ is defined as

$$
\alpha_{S}=\frac{A_{T}}{S}
$$

where $S\left[\mathrm{~m}^{2}\right]$ is the area covered by the test sample. Note that the edge area is included in the calculations of $S$ considering the four concretes as isotropic materials [38].

\section{Results}

The results of the measured sound absorption coefficients are reported in the graphs in Figures 5, 7 and 8 and discussed in separate sections, based on the tested conditions, i.e., thickness and mounting method for each concrete type (A-D). Figures 5, 7 and 8 present an immediate reading of the design factors considered within the sample typology to evidence improvements/deterioration given the mix design. Furthermore, the figures in Appendix B 
compare the results of considered panel samples (A-D) for a given design factor, in order to help the reader with a more immediate understanding of the differences between samples (A-D). In the end, more general conclusions are drawn to compare the performances of the different sample types. Moreover, the single index for weighted sound absorption $\left(\alpha_{w}\right)$ in SSRR measurements has been estimated and used for comparisons.

\subsection{Effect of Sample Thickness and Concrete Type}

Figure 5 shows the graphs of the four samples (A-D) for three different thicknesses of the single layers. Overall, the absorption spectra of panels $\mathrm{A}$ are uneven, and tend to provide poor absorption $(<0.25)$ at frequencies lower than $630 \mathrm{~Hz}$, while at higher frequencies, the sound absorption coefficients ranges between 0.40 and 0.70 for panels with either $40 \mathrm{~mm}$ or $60 \mathrm{~mm}$ thicknesses. The $20 \mathrm{~mm}$ thick panel features an absorption peak at $3150 \mathrm{~Hz}$, which reaches the value of 0.90 and provides a poor absorption $(<0.25)$ at frequencies lower than $2000 \mathrm{~Hz}$. The 40 and $60 \mathrm{~mm}$ panels present a higher absorption coefficient with respect to the $20 \mathrm{~mm}$ panels in the $500-2000 \mathrm{~Hz}$ frequency range.


Figure 5. Comparison of the absorption coefficients for samples (A-D) with different thicknesses obtained from multiple layer combinations $(20,40,20+20,60$, and $20+40 \mathrm{~mm})$. Sample (A): crushed normal weight aggregates 4-8 mm; Sample (B): round lightweight aggregates $4-8 \mathrm{~mm}$; Sample (C): round lightweight aggregates $2-4 \mathrm{~mm}$; Sample (D): round lightweight aggregates $0.5-1 \mathrm{~mm}$.

The absorption spectra of samples B are uneven and tend to provide poor absorption $(<0.25)$ at frequencies lower than $630 \mathrm{~Hz}$ for panels with either $40 \mathrm{~mm}$ or $60 \mathrm{~mm}$ thicknesses, while at higher frequencies the absorption coefficient ranges between 0.20 and 0.60 . The $20 \mathrm{~mm}$ thick panel features an absorption peak at $2500 \mathrm{~Hz}$ of about 0.60 and provides poor absorption $(<0.25)$ at frequencies lower than $1600 \mathrm{~Hz}$. This might be due to the curing process of the $40 \mathrm{~mm}$ sample, which might have led to lower porosity of these samples.

The absorption spectra of panels $\mathrm{C}$ are also slightly uneven and tend to provide poor absorption $(<0.25)$ at frequencies lower than $630 \mathrm{~Hz}$ for panels with either $40 \mathrm{~mm}$ or $60 \mathrm{~mm}$ thicknesses, while at higher frequencies, the absorption ranges between 0.40 and 0.80 . The $20 \mathrm{~mm}$ thick panel features an absorption peak around $4000 \mathrm{~Hz}$, achieving a value of 0.90 and provides poor absorption $(<0.25)$ at frequencies lower than $1600 \mathrm{~Hz}$. 
The absorption coefficient for this thickness becomes lower than 0.25 at frequencies below $2000 \mathrm{~Hz}$. The $60 \mathrm{~mm}$ sample reaches significant high values of absorption coefficient $(>0.40)$ at $800 \mathrm{~Hz}$, while the $40 \mathrm{~mm}$ panel at $1250 \mathrm{~Hz}$.

The absorption spectra of panel D are more even than the other three typologies, and tend to provide significant absorption $(>0.40)$ at frequencies higher than $630 \mathrm{~Hz}$ for panels with either $40 \mathrm{~mm}$ or $60 \mathrm{~mm}$ thicknesses, where the sound absorption ranges between 0.40 and 1 . The $20 \mathrm{~mm}$ thick panel feature an absorption peak between $2500 \mathrm{~Hz}$ and $4000 \mathrm{~Hz}$, achieving a value of 1.20; the peak is broader than those featured by $20 \mathrm{~mm}$ thick panels of types A-C. Values higher than 1 may occur in the measurements with finite sample size for materials with high absorption properties [39,40]. The $20 \mathrm{~mm}$ sample of panel D achieves significant absorption (>0.40) above $1000 \mathrm{~Hz}$, while for panels A-C, this occurred above $2500 \mathrm{~Hz}, 2000 \mathrm{~Hz}$, and $3150 \mathrm{~Hz}$, respectively. The sound absorbing performances of thicker panels are extended towards the lower frequencies, in the range below $1600 \mathrm{~Hz}$. Indeed, for the thicker panels $(40 \mathrm{~mm}$ and $60 \mathrm{~mm}$ ), the significant absorption range is extended in a similar way down to $630 \mathrm{~Hz}$.

\subsection{Effect of Sample Mounting in Multiple Layers}

The graphs in Figure 5 show the absorption coefficients of the four sample types both in the single layer and multiple layer configurations with panel thicknesses of 20, 40, and $60 \mathrm{~mm}$, for an easier comparison. Sample A graph shows that the sound-absorbing performances achieved when coupling two panels of $20 \mathrm{~mm}$ thick are comparable to those achieved by a single panel with a thickness of $40 \mathrm{~mm}$. A similar trend is observed comparing the $60 \mathrm{~mm}$ thick panel with the combination of $20+40 \mathrm{~mm}$ thick panels. However, there are some differences occurring above $1250 \mathrm{~Hz}$. It can be observed that above $2500 \mathrm{~Hz}$ both the $20+20 \mathrm{~mm}$ and the $20+40 \mathrm{~mm}$ combination show lower values of sound absorption compared to the 40 and the $60 \mathrm{~mm}$ single layers samples, respectively. It can be noticed that the multiple layer $20+40 \mathrm{~mm}$ of sample A outperforms the $60 \mathrm{~mm}$ sample only at the $800 \mathrm{~Hz}$ peak and in the frequency range 1250 to $2500 \mathrm{~Hz}$.

Sample B graph shows that the sound absorbing performances achieved when coupling two panels $20 \mathrm{~mm}$ thick are comparable to those achieved by a single panel with a thickness of $40 \mathrm{~mm}$. However, the combination $20+20$ outperforms the $40 \mathrm{~mm}$ single layer panel in the range of 1000 to $2000 \mathrm{~Hz}$. By contrast, the performances of the $60 \mathrm{~mm}$ thick panel are higher than those of $20+40 \mathrm{~mm}$ thick panels combined for frequencies higher than $1600 \mathrm{~Hz}$. The multiple layer $20+40$ outperforms the $60 \mathrm{~mm}$ sample in the range $630-1250 \mathrm{~Hz}$.

The results of Sample $C$ show that the sound absorbing performances achieved when coupling two panels that are $20 \mathrm{~mm}$ thick are slightly lower than those achieved by a single panel with a thickness of $40 \mathrm{~mm}$, particularly for frequencies range $800-2000 \mathrm{~Hz}$ and above $3150 \mathrm{~Hz}$. The performances of the $60 \mathrm{~mm}$ thick panel are comparable with those achieved by the combination of $20+40 \mathrm{~mm}$ thick panels. However, the multiple layer $20+40$ outperforms the $60 \mathrm{~mm}$ sample in the range 1250-2500 Hz.

Sample D results show that the sound absorbing performances achieved when coupling two panels $20 \mathrm{~mm}$ thick are comparable to those achieved by a single panel with a thickness of $40 \mathrm{~mm}$. A similar trend is observed comparing the performances achieved by a $60 \mathrm{~mm}$ thick panel with that of the combination of $20+40 \mathrm{~mm}$ thick panels. This might be due to the high and uniform porosity obtained for all the samples of type D compared to the other panel types, as seen in Figure 6. In these cases, further care should be put in the treatment of the mix design and its curing in samples A, B, and C, as heavier aggregates might sediment and result in nonuniform distribution of the pores within the panel and its front/back surfaces. 

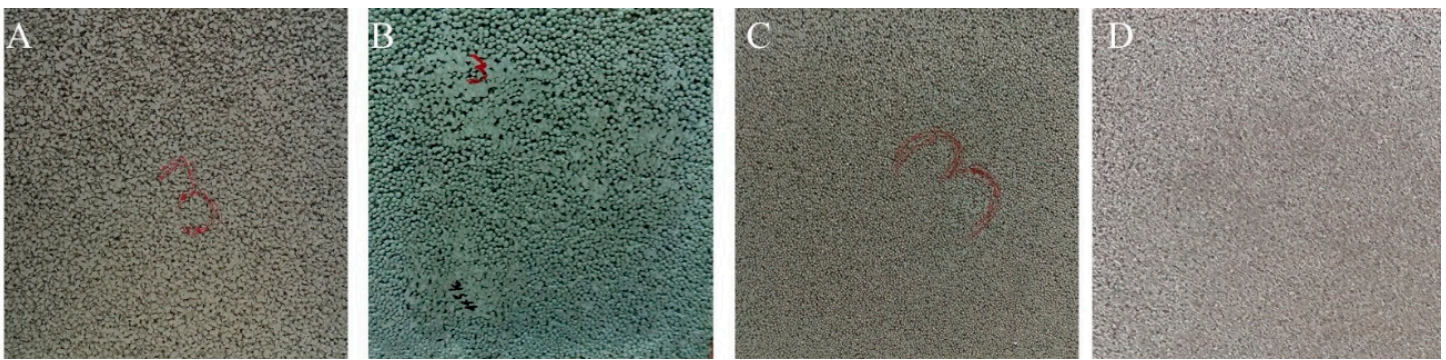

Figure 6. Back surface for Sample (A): crushed normal weight aggregates 4-8 mm; Sample (B): round lightweight aggregates 4-8 mm; Sample (C): round lightweight aggregates 2-4 mm; Sample (D): round lightweight aggregates 0.5-1 mm.

\subsection{Effect of Sample Mounting with an Air Gap}

The graphs in Figure 7 show the four sample types (A-D) mounted with an air gap of $50 \mathrm{~mm}$ between the panel and the rigid backing, i.e., the SSRR floor. The graph of Sample A shows that the performance is enhanced at the lower frequencies when an air gap is left between the panel of $20 \mathrm{~mm}$ and the backing, while the sound absorption at high frequencies decreases. The maximum peak is shifted at lower frequencies, i.e., at $\sim 630 \mathrm{~Hz}$, with an absorption coefficient of $\sim 0.60$. The $40 \mathrm{~mm}$ layer seems to be less affected by the presence of the air gap and the maximum peaks remain unvaried in frequency for this thickness. However, a slight decrease is reported at high frequencies and an increase of about 0.10 is observed at the peak value corresponding to $1250 \mathrm{~Hz}$.
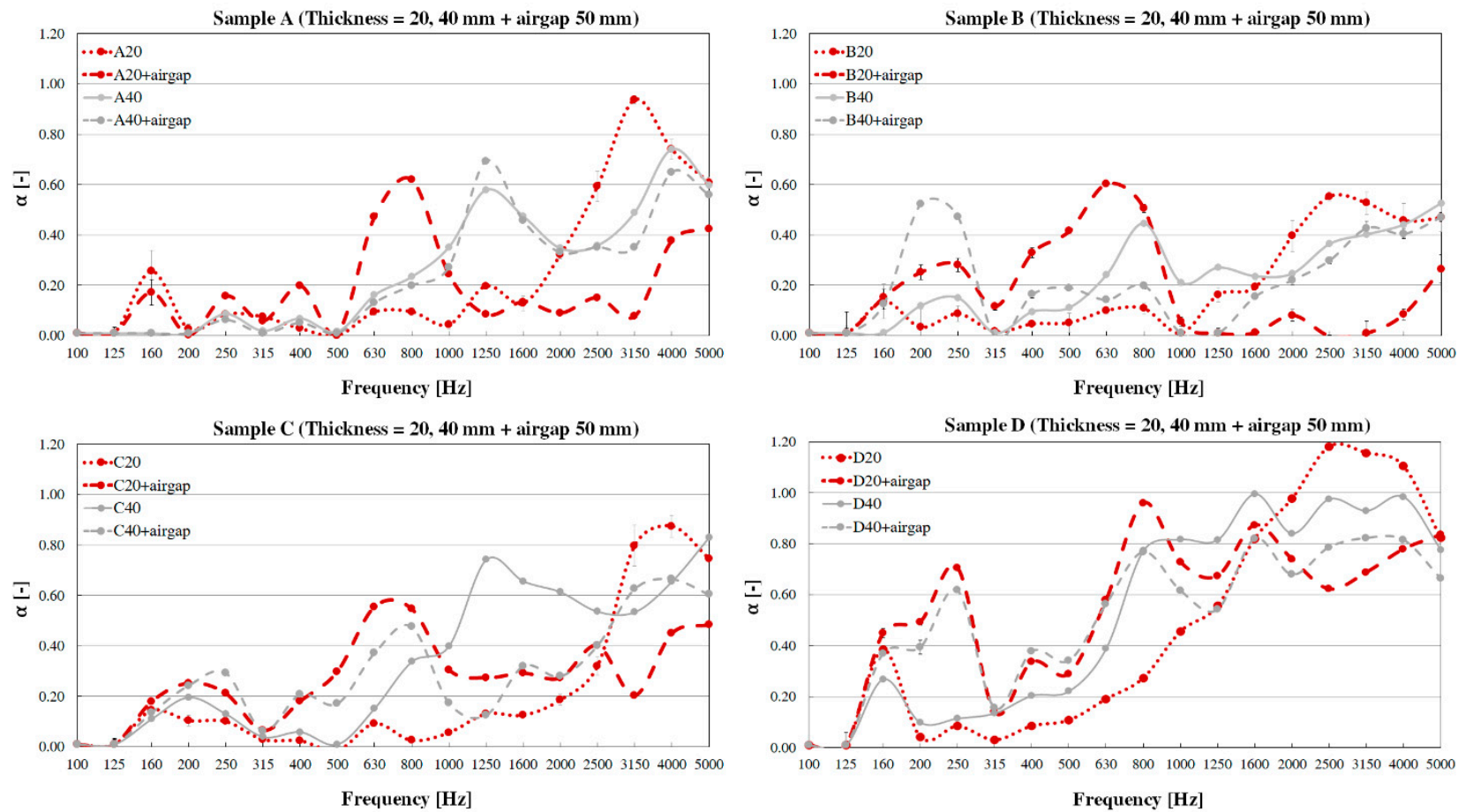

Figure 7. Comparison of the absorption coefficients for samples (A-D) of different thicknesses (20 and $40 \mathrm{~mm}) \mathrm{mounted}$ with an air gap of $50 \mathrm{~mm}$. Sample (A): crushed aggregates $4-8 \mathrm{~mm}$; Sample (B): round lightweight aggregates 4-8 mm; Sample (C): round lightweight aggregates 2-4 mm; Sample (D): round lightweight aggregates 0.5-1 $\mathrm{mm}$.

Sample B shows different trends for the $20 \mathrm{~mm}$ and $40 \mathrm{~mm}$ layers. However, when an air gap is left between the panels and the backing, the performance is enhanced at the lower frequencies for the $20 \mathrm{~mm}$ and $40 \mathrm{~mm}$ layers. The high frequency sound absorption decreases for the $20 \mathrm{~mm}$ layer when the air gap is added, while the maximum peak is shifted at lower frequencies, i.e., at $\sim 630 \mathrm{~Hz}$, with an absorption coefficient of $\sim 0.60$. The $40 \mathrm{~mm}$ 
layer seems to be less affected by the presence of the air gap at high frequencies above $2000 \mathrm{~Hz}$. Conversely, the air gap seems to decrease the absorption over the 630 to $2000 \mathrm{~Hz}$ range for the $40 \mathrm{~mm}$ layer. A peak value appears at the frequency of $200 \mathrm{~Hz}$ with a value of about 0.55 of the absorption coefficients.

Sample $C$ shows a decrease of the absorption coefficient at high frequencies for both $20 \mathrm{~mm}$ and $40 \mathrm{~mm}$ layers when an air gap is left between the panels and the backing. For the $20 \mathrm{~mm}$ panel, this is significant above $2500 \mathrm{~Hz}$, while for the $40 \mathrm{~mm}$ panel, it is more evident in the 1000 to $2500 \mathrm{~Hz}$ range. The performances are slightly enhanced at the lower frequencies in the range 315 to $800 \mathrm{~Hz}$ for the $20 \mathrm{~mm}$ sample and in the range 315 to $2500 \mathrm{~Hz}$ for the $40 \mathrm{~mm}$ sample, with the maximum peaks that are shifted at $630 \mathrm{~Hz}$ and $800 \mathrm{~Hz}$, respectively.

The sound-absorbing performances of sample D show a decrease at high frequencies when an air gap is left between the panels and the backing above $1600 \mathrm{~Hz}$ and above $800 \mathrm{~Hz}$ for the $20 \mathrm{~mm}$ and $40 \mathrm{~mm}$ panels, respectively. Nevertheless, the sound absorption coefficients in those ranges result above 0.55 . The performances are enhanced at the lower frequencies, where several peaks appear around $250 \mathrm{~Hz}, 400 \mathrm{~Hz}$, and $800 \mathrm{~Hz}$. The absorption coefficient increases for both thicknesses in the 160 to $630 \mathrm{~Hz}$ range when the air gap is added, showing a very similar trend for both $20 \mathrm{~mm}$ and $40 \mathrm{~mm}$ panels.

Effect of Sample Mounting with an Air Gap Filled with Porous Material

The previous sections showed that sample D presents the highest sound absorption coefficients extended over the broader range of frequencies. In order to further improve the performance of the combination of panel D with an air gap, another strategy has been used considering the air gap filled with porous material. The introduction of a rock wool layer in the air gap has been tested with the sample of $20 \mathrm{~mm}$ thickness only. Two thicknesses of the rock wool layer, that is, 30 and $50 \mathrm{~mm}$, have been introduced in the air gap. Recall that the air gap considered here is of $50 \mathrm{~mm}$. Therefore, the first layer of rock wool (30 mm) allowed to have a $20 \mathrm{~mm}$ air gap left between the concrete sample and the rock wool layer, while the $50 \mathrm{~mm}$ rock wool allowed to test a fully filled air gap.

Figure 8 shows that the with the insertion of $30 \mathrm{~mm}$ and $50 \mathrm{~mm}$ rock wool in the air gap the sound absorption coefficients have very similar trends above $630 \mathrm{~Hz}$. Generally, the combination of an air gap with a porous material (e.g., rock wool) is shown to improve the acoustic performance down to $250 \mathrm{~Hz}$. A peak value at $800 \mathrm{~Hz}$ is further increased when the air gap is filled with rock wool compared to the empty condition. Furthermore, a significant improvement is obtained in the 250 to $800 \mathrm{~Hz}$ frequency range reaching values of sound absorption coefficients of $0.60-0.90$.

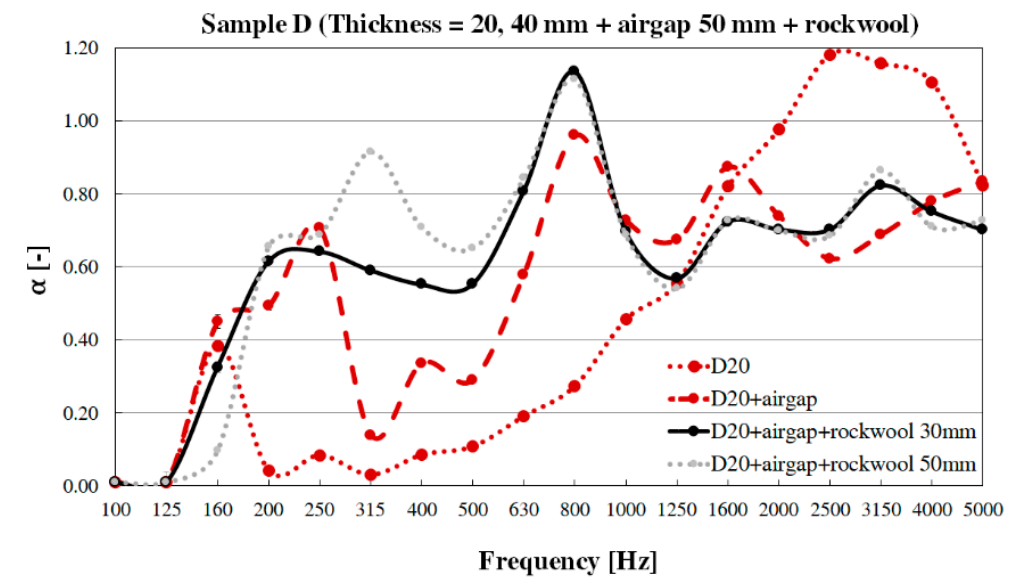

Figure 8. Sample D single layer of $20 \mathrm{~mm}$ combined with an air gap of $50 \mathrm{~mm}$ filled with a rock wool layer of 30 and $50 \mathrm{~mm}$. 


\subsection{Single Number Acoustic Index $\alpha_{w}$}

Based on the above results, the weighted sound absorption coefficients $\alpha_{w}$ derived from the SSRR measurements were calculated. These single indices are useful for an immediate and practical comparison of the performance of different conditions. The higher the $\alpha_{w}$ values, the better the material capability in sound absorption. Their values normally range from 0 to 1 , with 1 meaning $100 \%$ sound absorption.

The weighted sound absorption coefficient $\alpha_{w}$ is derived from practical sound absorption coefficients, $\alpha_{p}$ which is calculated as an average of the one-third octave sound absorption coefficients within the octave in accordance with ISO 11,654 [41]. Weighted sound absorption coefficient $\alpha_{w}$ can be obtained with the reference curve $\left(\alpha_{250}=0.8 ; \alpha_{500}=1\right.$; $\alpha_{1000}=1 ; \alpha_{2000}=1 ; \alpha_{4000}=0.9$ ), which is shifted in steps of 0.05 towards the $\alpha_{p}$ values until the sum of unfavorable deviations is less or equal to 0.10 . The unfavorable deviations occur when the measured value is lower than the value of the reference curve. Finally, the weighted sound absorption coefficient is the value of the adjusted reference curve at $500 \mathrm{~Hz}$.

Table 3 shows that there are a few differences among the single indices within each concrete data. It is evident from these values that the highest performance is obtained for panel type $\mathrm{D}$. The $\alpha_{w}$ values for the single layer of type D samples become significant $(>0.40)$ for a thickness of $60 \mathrm{~mm}$. The single layers of $20 \mathrm{~mm}$ and $40 \mathrm{~mm}$ present an improvement of the $\alpha_{w}$ values when they are mounted with an air gap behind $\left(\alpha_{w}=0.50\right)$. This mounting condition performance is further improved when the air gap is filled with a porous material. It can be noticed that when the entire gap is filled with rock wool $(50 \mathrm{~mm})$, the highest $\alpha_{w}$ is obtained. A significant improvement due to the air gap is also obtained for sample C, while a slight improvement is reported for sample A. Conversely, depending on the sample thicknesses, sample B values of $\alpha_{w}$ are either not affected or reduced when the air gap is added at the back of the $20 \mathrm{~mm}$ and $40 \mathrm{~mm}$ thick layers, respectively.

Table 3. Comparison of single acoustic indices related to the weighted absorption coefficient $\left(\alpha_{w}\right)$ for the four concrete types (A-D).

\begin{tabular}{ccccc}
\hline Sample Characteristics & A & B & C & D \\
\hline $20 \mathrm{~mm}$ & 0.10 & 0.10 & 0.10 & 0.20 \\
$40 \mathrm{~mm}$ & 0.15 & 0.25 & 0.15 & 0.30 \\
$60 \mathrm{~mm}$ & 0.25 & 0.25 & 0.25 & 0.45 \\
$20+20 \mathrm{~mm}$ & 0.15 & 0.25 & 0.15 & 0.30 \\
$20+40 \mathrm{~mm}$ & 0.20 & 0.25 & 0.25 & 0.40 \\
$20 \mathrm{~mm}+50 \mathrm{~mm}$ air gap & 0.20 & 0.10 & 0.35 & 0.50 \\
$40 \mathrm{~mm}+50 \mathrm{~mm}$ air gap & 0.20 & 0.10 & 0.30 & 0.50 \\
$20 \mathrm{~mm}+50 \mathrm{~mm}$ air gap (rock wool 30 mm) & & & & 0.70 \\
$20 \mathrm{~mm}+50 \mathrm{~mm}$ air gap (rock wool 50 mm) & & & & 0.75 \\
\hline
\end{tabular}

\section{Discussion}

Given the results herein, a few aspects can be highlighted with respect to previous findings presented in Section 1 and Appendix A. The sound-absorbing properties of the panels under examination (i.e., A-D) were generally found to be extended towards the lower frequencies with increasing thicknesses of the panels (i.e., $20 \mathrm{~mm}, 40 \mathrm{~mm}$, or $60 \mathrm{~mm}$ ). The result is coherent with the findings of previous studies, such as in $[13,18,21]$. However, panel B exhibits an unexpected behavior, as while the sound absorbing properties of the thicker panels are higher at lower frequencies compared to the $20 \mathrm{~mm}$ sample, as it can be seen in the 500 to $1600 \mathrm{~Hz}$ frequency range, the $20 \mathrm{~mm}$ thick sample outperforms the $40 \mathrm{~mm}$ thick one in the range of 1600 to $4000 \mathrm{~Hz}$. Moreover, no peak shift towards the lower frequencies is reported for the $60 \mathrm{~mm}$ thick panel compared to the $40 \mathrm{~mm}$ thick one, as both present an absorption peak at $800 \mathrm{~Hz}$. These two aspects may suggest that the superficial and inner porosity of panels $B$ are not uniform among the different thicknesses. Moreover, it can be argued that for this typology that the thickness threshold is $\sim 40 \mathrm{~mm}$, 
i.e., no further increase of the absorption coefficient below $800 \mathrm{~Hz}$ is obtained with the thickness increase from 40 to $60 \mathrm{~mm}$ [7]. Sample D outperforms the other typologies and confirms that its superficial and inner structures are made of many small and uniformly distributed pores and apertures connected with each other and with the outer surface [11].

When comparing samples with round lightweight aggregates, i.e., B-D, it can be observed that there is a decrease in the sound absorption when the aggregate size increases from $0.5-1 \mathrm{~mm}$ (sample D) to $4-8 \mathrm{~mm}$ (sample B). This is due to an increase in the median pore size when increasing aggregate size as shown in [21], which would reduce the tortuosity of the pore network, thus resulting in lower absorption values. Indeed, sample D has a lower water permeability (Table 1), which is inversely correlated to tortuosity [42]. Moreover, note that sample A with crushed normal weight aggregates results in higher values of the absorption coefficient when compared to sample B, which has similar void ratio $(25 \%)$ and aggregate dimensions (4-8 $\mathrm{mm}$ ) to sample $\mathrm{A}$, but features different aggregate shapes and densities, i.e., round lightweight aggregates. This might be due to a higher tortuosity enabled by internal pores with varied size connected to the surface, which is coherent with the aspects highlighted in [11]. This kind of difference was not observed in previous studies, that is, the work in [22], where only slight differences between round-shape (lightweight) and irregular shape (normal weight) aggregates with the same gradation were found.

When considering panels composed of two layers, the presented results have highlighted some discrepancies between the sound absorbing performances of multilayered panels and those of a single layer panel of the same thickness in case of panel samples A-C. Conversely, samples D in the multilayered and single layer solution of equal thickness exhibit similar performances. This behavior may be linked to the different degrees of uniformity in the pore distribution of the different panel samples. In samples D, both sides of the panel present a uniform distribution of the pores apertures and the measurement results also suggest a higher connection of the internal pores to the surface as highlighted in [11]. Differently, for samples A-C, the closed pores presented in the back side of the panels (Figure 6) may not allow full activation of the absorption of the second layer. This highlights that the sound absorption performances of such sample may be improved if greater attention is paid during the treatment of the mix design and its curing in samples.

By comparing the sound absorbing performances of the different panel types measured mounted with an air gap of $50 \mathrm{~mm}$, it emerges that the panel type D outperforms the other typologies. It presents a more uniform frequency-dependent sound absorption, a broader frequency range of high values of absorption coefficient, and absorption coefficients higher than those of other panel typologies. The performances of panels type $C$ are slightly better than those of panels A and B. The worst performance is presented by panel type B, which is generally associated with the lower sound absorbing coefficient throughout the spectrum. This might be due to the effect of regular and bigger aggregates, which lead to reduced tortuosity of the pore network [21]. However, the behavior of samples A, B and C does not change much with the air gap, suggesting that the sound is at least partly blocked by the sample. Indeed, as it was highlighted also for the multilayer investigation, for the other three typologies the back sides of the panels (Figure 6) present a higher number of closed pores, which do not allow to fully activate the absorption due to the combination with the air gap.

Generally, when considering the additional layer of air gap, note that the performance of the $20 \mathrm{~mm}$ sample behaves as a layer of microperforated panel mounted with an air gap, i.e., presenting a clear sound absorption coefficient peak at low frequencies with poor values at higher frequencies [7]. This similarity is more evident for samples A and B, which are expected to have pore networks with lower tortuosity due to the greater dimension of the aggregates $(4-8 \mathrm{~mm})$ as presented in [21]. The $40 \mathrm{~mm}$ sample shows a similar behavior, which can resemble that of a multilayer microperforated panel (MPP) [43]. In this case, the thickness of the panel allows for a higher tortuosity of the pore network, which still allows for some absorption at higher frequencies. Indeed, the microperforated panel sound 
absorption model presented by Maa [44,45] has been used in several studies to describe the acoustic behavior of concrete.

By partially or completely filling the air gap at the back of the $20 \mathrm{~mm}$ thick sample D with rock wool as porous material within the air gap, the sound absorbing performances were reported to improve down to $250 \mathrm{~Hz}$. This is because the air resonance in the air gap and porous material layer is further damped by the porous material layer. This is coherent with the findings related to MPPs [43] and highlights the improvements on absorption with broader bandwidth and lower frequencies efficiency. These solutions' results are appropriate for several outdoor applications dealing with railway noise and traffic noise reductions and feature a spectrum of interest in the range of 125 to $4000 \mathrm{~Hz}$ [46]. Moreover, the investigated mounting systems could be integrated with structural multilayer building facades [47,48].

Note that it was observed that although sample D results with the highest performance in terms of evenness and rate, it presents poor performances related to wear resistance compared to the other types, which may hamper their application in actual scenarios if no facings or other protective solutions are used. Another option is to use panels of type $B$ and $C$, which, when coupled in layers of $20+40 \mathrm{~mm}$, reach sound-absorbing performances close to those of the same configuration of panels type $\mathrm{D}$ for frequencies higher than $800 \mathrm{~Hz}$. Alternatively, a systematic investigation may be useful to detect the thresholds values of the concrete parameters (e.g., paste volume) in order to obtain acceptable mechanical properties and still preserve highly efficient acoustical properties.

The study highlights the necessity to develop a higher number of experimental investigations by controlling the variables of the mix design in more systematic way. This approach has been possible to follow only through model applications as in [45].

\section{Conclusions}

The present study has been carried out in order to characterize the sound absorbing performances of a set of porous concrete panels varying in concrete mix design (A-D), thickness and mounting method. The measurements have been conducted in the 1:5 scale reverberation room of the Politecnico di Torino, in accordance with the ISO 354-1:2003 standard. The sound absorbing performances of the different panels have been described as $1 / 3$ octave band and as weighted sound absorption coefficient $\alpha_{w}$. The following conclusions have been drawn.

(i) The mix design with the smallest round lightweight aggregate dimensions $(0.5-1 \mathrm{~mm})$, referred to as panel $\mathrm{D}$, gave the most effective sound absorption coefficient for all the three sample thicknesses as well as for the mounting condition with an air gap at their back. It was shown that the worst performing mix design feature round lightweight aggregate with the greater dimensions $(4-8 \mathrm{~mm})$ referred to as panel $\mathrm{B}$.

(ii) Samples with crushed normal weight aggregates of 4-8 $\mathrm{mm}$, referred to as panel A, showed higher values of absorption coefficients compared to samples with round lightweight aggregates of the same dimensions. The performance is comparable to that of the sample with round lightweight aggregates of smaller gradation $(2-4 \mathrm{~mm})$ referred to as panel $C$. This was attributed to the pores dimensions and inner distribution which affects the pores tortuosity.

(iii) The sound-absorbing performances of the porous concrete panels tend to increase at low frequencies for greater panel thicknesses. In most cases, solutions with single panels or double-layered panels of an equivalent thickness provide similar performances. This mounting solution could be useful in practice for modular solutions and to limit the need for different formwork thicknesses.

(iv) The mounting method is shown to greatly influence the sound-absorbing performances. For all porous concrete types considered, the sound absorption performances are enhanced for lower frequencies by leaving a $50 \mathrm{~mm}$ air gap behind the panel. However, the air gap significantly lowers the high frequencies performance of the thinnest samples $(20 \mathrm{~mm})$. 
(v) The frequency dependent absorption coefficient and the weighted absorption coefficient $\alpha_{w}$ comparisons showed that, depending on the mounting method, the performance of the concrete samples with aggregate dimensions of $0.5-1 \mathrm{~mm}$, i.e., panel $\mathrm{D}$, can be further improved. The $\alpha_{w}$ reaches values 0.50 and 0.75 for the condition with an empty air gap of $50 \mathrm{~mm}$ and air gap completely filled with a rock wool layer, respectively. These values are comparable to those of most used conventional porous materials.

Note that the mix design mechanical properties remain a crucial aspect that need to be considered when the applicability of such materials is discussed. It was observed that the material with higher acoustic performance (round lightweight aggregate of $0.5-1 \mathrm{~mm}$ ) presents poor performances related to wear resistance, which makes the application of such panels in actual scenario impractical. Therefore, we endorse further testing in the attempt to find the most performing solution balancing sound absorption with wear resistance performances. Alternatively, when wear resistance is required, it is possible to use panels of type B and C, which, when coupled in layers of $20+40 \mathrm{~mm}$, reach sound-absorbing performances close to those of the same configuration of panels type $\mathrm{D}$ for frequencies higher than $800 \mathrm{~Hz}$.

Further research could be conducted along this line of research to explore other mix design and mounting method strategies to hopefully increase awareness about the potential benefits of the application of sound absorbing porous concrete in the frame of the architectural and urban design strategies. Such research may include (1) acoustic absorption of materials with blended aggregates of different dimensions, weights and shapes, (2) acoustic absorption for alternative mounting methods, (3) acoustic absorption modeling of porous concrete of single layers and multilayer structure, and (4) possible applications in case studies for outdoor and indoor environments.

Author Contributions: Conceptualization, L.S., A.A., G.V., and D.Z.; methodology, L.S. and A.A.; formal analysis, L.S. and E.B.; investigation, L.S. and E.B.; resources, G.V. and D.Z.; data curation, L.S. and E.B.; writing—original draft preparation, L.S. and E.B.; writing—review and editing, L.S., A.A., E.B., and G.V.; visualization, L.S. and E.B.; supervision, L.S. and A.A.; project administration, L.S., A.A., and G.V.; funding acquisition, A.A. and L.S. All authors have read and agreed to the published version of the manuscript.

Funding: The work has been funded by CEMEX Innovation Holding AG.

Institutional Review Board Statement: Not applicable.

Informed Consent Statement: Not applicable.

Data Availability Statement: Not applicable.

Acknowledgments: The authors are grateful to Marta Bivanti and Giuseppe Vannelli for their contribution to the small-scale reverberation room measurements. They would like to thank the colleagues of CEMEX Innovation Holding AG who helped in manufacturing the samples.

Conflicts of Interest: The authors declare no conflict of interest.

\section{Appendix A}

Summary of the main findings of past studies on the effect on sound absorption of aggregate size. 
Table A1. Summary of the main findings of past studies on the effect on sound absorption of aggregate size, dimensions and type, and panel thickness. Abbreviations used in the table body: lightweight (LW); normal weight (NW); limestone (LS); aggregate (aggr.); sound absorption $(\alpha)$.

\begin{tabular}{|c|c|c|c|c|}
\hline $\begin{array}{l}\text { Mix Design } \\
\text { Variable }\end{array}$ & Effect [Refs] & Details & Method & Main Findings \\
\hline \multirow{7}{*}{$\begin{array}{l}\text { Aggregate } \\
\text { size }\end{array}$} & Influence [11] & $\begin{array}{c}0-2 \mathrm{~mm} / \\
1-5 \mathrm{~mm} / 1-3 \mathrm{~mm}\end{array}$ & Single sized & $1-3 \mathrm{~mm}$ and $1-5 \mathrm{~mm}$ aggr. result in higher $\alpha$ \\
\hline & \multirow[b]{2}{*}{ Influence $[19,21]$} & \multirow{2}{*}{$\begin{array}{l}2.36-4.75 \mathrm{~mm} / \\
4.75-9.5 \mathrm{~mm} / \\
9.5-12 \mathrm{~mm}\end{array}$} & Single sized & $\begin{array}{l}\text { Concrete with } 2.36-4.75 \mathrm{~mm} \text { and } 4.75-9.5 \mathrm{~mm} \text { aggr. } \\
\text { provide higher } \alpha \text { than that with } 9.5-12 \mathrm{~mm} \text { aggr. }\end{array}$ \\
\hline & & & Blended & $\begin{array}{l}\text { The effect of blending aggr. on } \alpha \text { varies depending } \\
\text { on the aggr. size. Best performance with blends of } \\
2.36-4.75 \mathrm{~mm} \text { and } 4.75-9.5 \mathrm{~mm} \text { aggr. }\end{array}$ \\
\hline & $\begin{array}{l}\text { Limited } \\
\text { influence [22] }\end{array}$ & $\begin{array}{l}4-8 \mathrm{~mm} / 8-12 \mathrm{~mm} / \\
12-19 \mathrm{~mm}\end{array}$ & Single sized & $\begin{array}{l}\text { Slight increase in } \alpha \text { for smaller aggr. }(4-8 \mathrm{~mm}) \\
\text { compared to bigger ones }\end{array}$ \\
\hline & \multirow[b]{2}{*}{ Influence $[12,13]$} & \multirow{2}{*}{$\begin{array}{l}>5 \mathrm{~mm} / \\
1.25-5 \mathrm{~mm} / \\
<1.25 \mathrm{~mm}\end{array}$} & Single sized & $\begin{array}{l}\text { Concrete with aggr. dimensions }>5 \mathrm{~mm} \text { feature } \\
\text { higher } \alpha \text { than alternatives with smaller aggr. }\end{array}$ \\
\hline & & & Layered & $\begin{array}{l}\text { Three-layered solutions with the aggr. dimensions } \\
\text { (from exterior layer) of }>5 \mathrm{~mm} / 1.25-5 \mathrm{~mm} / \\
<1.25 \mathrm{~mm} \text { result in the higher } \alpha\end{array}$ \\
\hline & No influence [22] & $\begin{array}{l}8-13 \mathrm{~mm} / \\
13-19 \mathrm{~mm}\end{array}$ & Layered & $\begin{array}{l}\text { The variation of aggr. dimensions in the back layer } \\
\text { does not affect the } \alpha\end{array}$ \\
\hline \multirow{10}{*}{$\begin{array}{l}\text { Aggregate } \\
\text { material }\end{array}$} & \multirow{3}{*}{ Influence [11] } & $\begin{array}{l}\text { Expanded } \\
\text { perlite/slag/ } \\
\text { clay ceramsite }\end{array}$ & Single type & $\begin{array}{l}\text { Expanded perlite aggr. provides the highest } \alpha \text { with } \\
\text { respect to slag and clay ceramsite }\end{array}$ \\
\hline & & \multirow{2}{*}{$\begin{array}{l}\text { Expanded } \\
\text { perlite/slag }\end{array}$} & $\%$ replacement & $\begin{array}{l}\text { The } \alpha \text { decrease with the relative increase in content } \\
\text { of slag over expanded perlite aggr. }\end{array}$ \\
\hline & & & Layered & $\begin{array}{l}\text { The combination of } 8 \mathrm{~cm} \text { slag (lower layer) and } \\
12 \mathrm{~cm} \text { expanded perlite (upper layer) is the most } \\
\text { performing one among those considered }\end{array}$ \\
\hline & Influence [22] & $\begin{array}{l}\text { LW + NW } \\
\text { aggr./only } \\
\text { LW aggr. }\end{array}$ & Layered & $\begin{array}{l}\text { Layered solution with LW aggr. in the exterior } \\
\text { layer and NW aggr. in the back layer outperform } \\
\text { single layer with LW aggr. }\end{array}$ \\
\hline & $\begin{array}{c}\text { Limited } \\
\text { influence [22] }\end{array}$ & NW/LW aggr. & Single type & $\begin{array}{l}\text { A slight increase in } \alpha \text { is reported for crushed NW } \\
\text { aggr. in comparison to rounded LW ones with } \\
\text { similar sizes. The results do not seem consistent } \\
\text { when varying the thickness of the concrete panel }\end{array}$ \\
\hline & Influence [13] & $\begin{array}{l}\text { Bottom ash vs. } \\
\text { normal aggr. }\end{array}$ & Single type & $\begin{array}{c}\text { Bottom ash concrete results in higher or } \\
\text { comparable } \alpha \text { than a typical porous concrete sample }\end{array}$ \\
\hline & Influence [23] & $\begin{array}{l}\text { Crumb rubber / fine } \\
\text { normal aggr. }\end{array}$ & $\%$ replacement & $\begin{array}{c}\text { Replacing fine aggr. with crumb rubber ones } \\
\text { increase } \alpha \text {, for increasing percentages of } \\
\text { replacement (up to } 20 \% \text { ) }\end{array}$ \\
\hline & Influence [24] & $\begin{array}{l}\text { Bottom } \\
\text { ash/recycled/ } \\
\text { LS aggr. }\end{array}$ & $\%$ replacement & $\begin{array}{l}\text { The replacement of LS aggr. with bottom ash and } \\
\text { recycled aggr. result in higher } \alpha \text {; the } 2 \text { nd peak } \\
\text { shifts towards the higher frequencies for higher } \\
\text { percentages of replacement }\end{array}$ \\
\hline & No influence [20] & $\begin{array}{l}\text { Recycled aggr./ } \\
\text { LS aggr. }\end{array}$ & $\%$ replacement & $\begin{array}{c}\text { With equal target void ratio, the effect of replacing } \\
\text { LS aggr. with recycled ones had very } \\
\text { slight influence }\end{array}$ \\
\hline & Influence [25] & $\begin{array}{c}\text { Cenosphere } \\
\text { addition }\end{array}$ & Single type & $\begin{array}{l}\text { The increase of volume fraction of cenospheres } \\
\text { result in increased } \alpha \text { from } 0 \text { to } 20 \text { to } 40 \% \text {; further } \\
\text { increases result in lower performance }\end{array}$ \\
\hline
\end{tabular}


Table A1. Cont.

\begin{tabular}{|c|c|c|c|c|}
\hline $\begin{array}{c}\text { Mix Design } \\
\text { Variable }\end{array}$ & Effect [Refs] & Details & Method & Main Findings \\
\hline $\begin{array}{l}\text { Aggregate } \\
\text { shape }\end{array}$ & $\begin{array}{c}\text { Limited } \\
\text { influence [22] }\end{array}$ & $\begin{array}{c}\text { Crushed/rounded } \\
\text { aggr. }\end{array}$ & Single type & $\begin{array}{l}\text { A slight increase of } \alpha \text { is reported for crushed NW } \\
\text { aggregates in comparison to rounded LW ones with } \\
\text { similar sizes. The results do not seem consistent } \\
\text { when varying the thickness of the concrete panel }\end{array}$ \\
\hline Thickness & $\begin{array}{l}\text { Influence } \\
{[13,18,21]}\end{array}$ & $\begin{array}{l}\text { Panel thickness } \\
\text { variation }\end{array}$ & Single layer & $\begin{array}{c}\text { The peak of the } \alpha \text { is displaced to lower frequencies } \\
\text { for increasing panel thicknesses }\end{array}$ \\
\hline
\end{tabular}

\section{Appendix B}

Graphs supplemental to the results provided as a direct comparison between different concrete typologies regarding thickness variation, multilayer combination, and mounting condition over an airgap.
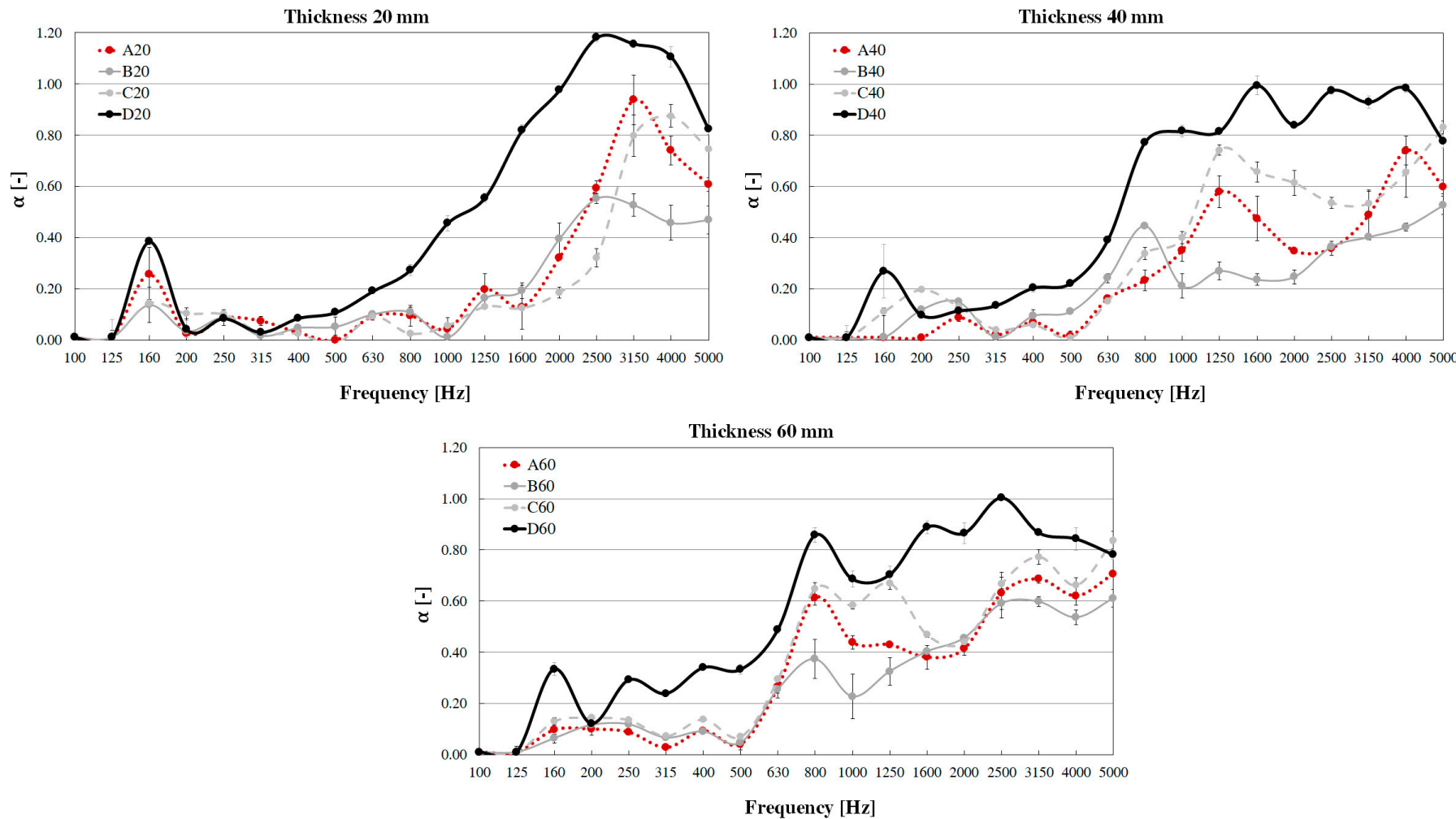

Figure A1. Comparison of the absorption coefficients for samples A-D with different thicknesses. Sample A: crushed normal weight aggregates 4-8 mm; Sample B: round lightweight aggregates 4-8 mm; Sample C: round lightweight aggregates 2-4 mm; Sample D: round lightweight aggregates $0.5-1 \mathrm{~mm}$. 

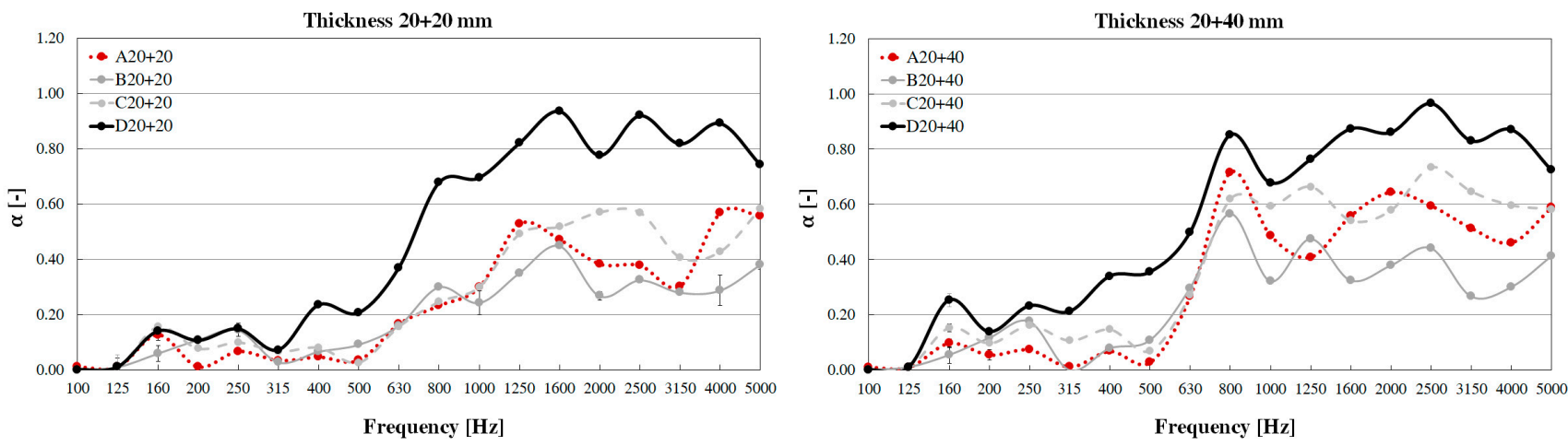

Figure A2. Comparison of the absorption coefficients for samples A-D with different thicknesses obtained from multiple layer combinations $(20+20$ and $20+40 \mathrm{~mm})$. Sample A: crushed normal weight aggregates 4-8 mm; Sample B: round lightweight aggregates 4-8 mm; Sample C: round lightweight aggregates 2-4 mm; Sample D: round lightweight aggregates $0.5-1 \mathrm{~mm}$.
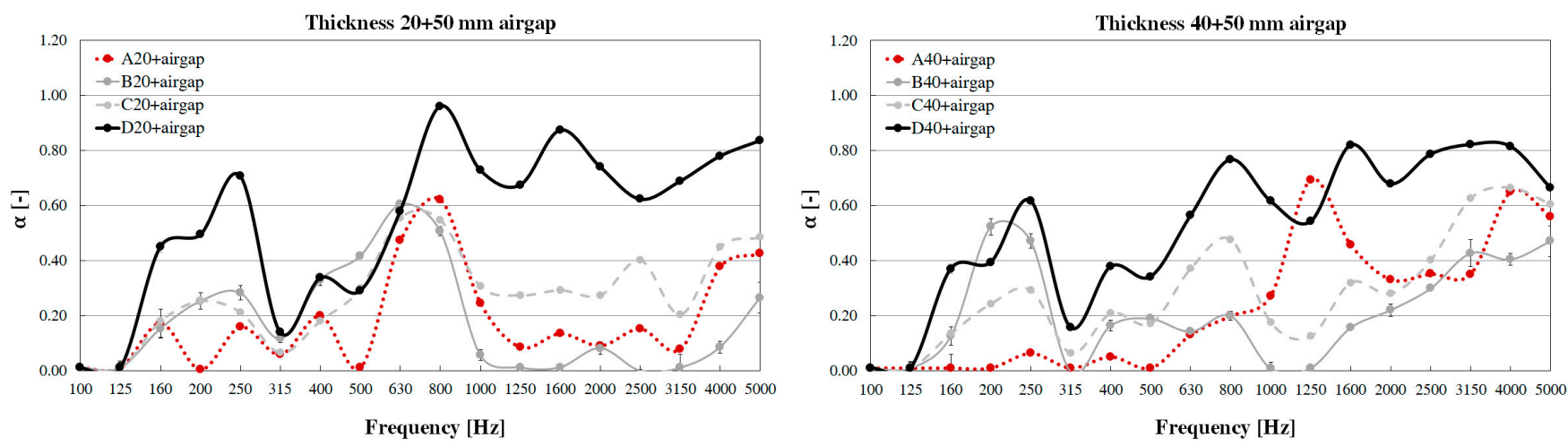

Figure A3. Comparison of the absorption coefficients for samples A-D with different thicknesses (20 and $40 \mathrm{~mm}) \mathrm{mounted}$ over an airgap of $50 \mathrm{~mm}$. Sample A: crushed normal weight aggregates 4-8 mm; Sample B: round lightweight aggregates 4-8 mm; Sample C: round lightweight aggregates 2-4 mm; Sample D: round lightweight aggregates 0.5-1 mm.

\section{References}

1. Sanchez, G.M.E.; Van Renterghem, T.; Thomas, P.; Botteldooren, D. The Effect of Street Canyon Design on Traffic Noise Exposure along Roads. Build. Environ. 2016, 97, 96-110. [CrossRef]

2. Badino, E.; Manca, R.; Shtrepi, L.; Calleri, C.; Astolfi, A. Effect of Façade Shape and Acoustic Cladding on Reduction of Leisure Noise Levels in a Street Canyon. Build. Environ. 2019, 157, 242-256. [CrossRef]

3. Calleri, C.; Shtrepi, L.; Armando, A.; Astolfi, A. Evaluation of the Influence of Building Façade Design on the Acoustic Characteristics and Auditory Perception of Urban Spaces. Build. Acoust. 2018, 25, 77-95. [CrossRef]

4. Taghipour, A.; Sievers, T.; Eggenschwiler, K. Acoustic Comfort in Virtual Inner Yards with Various Building Facades. Int. J. Environ. Res. Public Health 2019, 16, 249. [CrossRef] [PubMed]

5. Yang, W.; Jeon, J.Y. Design Strategies and Elements of Building Envelope for Urban Acoustic Environment. Build. Environ. 2020, 182. [CrossRef]

6. Adams, T. Sound Materials; Frame Publisher: Amsterdam, The Netherlands, 2016; ISBN 94-92311-01-1.

7. Cox, T.J.; D'Antonio, P. Acoustic Absorbers and Diffusers: Theory, Design and Application, 3rd ed.; Taylor \& Francis: Abingdon-onThames, UK, 2017; ISBN 978-0-367-65841-0.

8. Neithalath, N.; Weiss, J.; Olek, J. Characterizing Enhanced Porosity Concrete Using Electrical Impedance to Predict Acoustic and Hydraulic Performance. Cem. Concr. Res. 2006, 36, 2074-2085. [CrossRef]

9. Ibrahim, A.; Mahmoud, E.; Yamin, M.; Patibandla, V.C. Experimental Study on Portland Cement Pervious Concrete Mechanical and Hydrological Properties. Constr. Build. Mater. 2014, 50, 524-529. [CrossRef]

10. Scholz, M.; Grabowiecki, P. Review of Permeable Pavement Systems. Build. Environ. 2007, 42, 3830-3836. [CrossRef]

11. Zhao, C.; Wang, P.; Wang, L.; Liu, D. Reducing Railway Noise with Porous Sound-Absorbing Concrete Slabs. Adv. Mater. Sci. Eng. 2014, 2014, 1-11. [CrossRef]

12. Arenas, C.; Vilches, L.F.; Cifuentes, H.; Leiva, C.; Vale, J.; Fernández-Pereira, C. Development of Acoustic Barriers Mainly Composed of Co-Combustion Bottom Ash. In Proceedings of the World of Coal Ash (WOCA) Conference, Denver, CO, USA, 9-12 May 2011. 
13. Arenas, C.; Leiva, C.; Vilches, L.F.; Cifuentes, H. Use of Co-Combustion Bottom Ash to Design an Acoustic Absorbing Material for Highway Noise Barriers. Waste Manag. 2013, 33, 2316-2321. [CrossRef] [PubMed]

14. ACI Committee 522-10. Report on Pervious Concrete; American Concrete Institute: Farmington Hills, MI, USA, 2010; ISBN 978-0-87031-364-6.

15. Kovác, M.; Sicáková, A. Pervious Concrete as a Sustainable Solution for Pavementsin Urban Areas. In Proceedings of the 10th International Conference "Environmental Engineering"; VGTU Technika, Vilnius, Lithuania, 27-28 April 2017.

16. Kosmatka, S.H.; Wilson, M.L. Design and Control. of Concrete Mixtures, 15th ed.; Portland Cement Association: Skokie, IL, USA, 2011; Volume EB001, ISBN 0-89312-272-6.

17. Tie, T.S.; Mo, K.H.; Putra, A.; Loo, S.C.; Alengaram, U.J.; Ling, T.-C. Sound Absorption Performance of Modified Concrete: A Review. J. Build. Eng. 2020, 30, 101219. [CrossRef]

18. Neithalath, N. Development and Characterization of Acoustically Efficient Cementitious Materials. Ph.D. Thesis, Purdue University, West Lafayette, IN, USA, 2004.

19. Neithalath, N.; Weiss, J.; Olek, J. Improving the Acoustic Absorption of Enhanced Porosity Concrete with Fiber Reinforcement. In Proceedings of the International RILEM Symposium on Concrete Science and Engineering: A Tribute to Arnon Bentur, Evanston, IL, USA, 21-24 March 2004; Kovler, K., Marchand, J., Mindess, S., Weiss, J., Eds.; RILEM Publications SARL: Paris, France, 2004.

20. Park, S.B.; Seo, D.S.; Lee, J. Studies on the Sound Absorption Characteristics of Porous Concrete Based on the Content of Recycled Aggregate and Target Void Ratio. Cem. Concr. Res. 2005, 35, 1846-1854. [CrossRef]

21. Marolf, A.; Neithalath, N.; Sell, E.; Wegner, K.; Weiss, J.; Olek, J. Influence of Aggregate Size and Gradation on Acoustic Absorption of Enhanced Porosity Concrete. ACI Mater. J. 2004, 101, 82-91.

22. Kim, H.K.; Lee, H.K. Influence of Cement Flow and Aggregate Type on the Mechanical and Acoustic Characteristics of Porous Concrete. Appl. Acoust. 2010, 71, 607-615. [CrossRef]

23. Sukontasukkul, P. Use of Crumb Rubber to Improve Thermal and Sound Properties of Pre-Cast Concrete Panel. Constr. Build. Mater. 2009, 23, 1084-1092. [CrossRef]

24. Ngohpok, C.; Sata, V.; Satiennam, T.; Klungboonkrong, P.; Chindaprasirt, P. Mechanical Properties, Thermal Conductivity, and Sound Absorption of Pervious Concrete Containing Recycled Concrete and Bottom Ash Aggregates. KSCE J. Civ. Eng. 2018, 22, 1369-1376. [CrossRef]

25. Tiwari, V.; Shukla, A.; Bose, A. Acoustic Properties of Cenosphere Reinforced Cement and Asphalt Concrete. Appl. Acoust. 2004, 65, 263-275. [CrossRef]

26. Fediuk, R.; Amran, M.; Vatin, N.; Vasilev, Y.; Lesovik, V.; Ozbakkaloglu, T. Acoustic Properties of Innovative Concretes: A Review. Materials 2021, 14, 398. [CrossRef]

27. EN 933-2:2020. Tests for Geometrical Properties of Aggregates. Part. 2: Determination of Particle Size Distribution-Test. Sieves, Nominal Size of Apertures; The British Standards Institution: London, UK, 2020.

28. EN 1097-6:2013. Tests for Mechanical and Physical Properties of Aggregates. Part. 6: Determination of Particle Density and Water Absorption; The British Standards Institution: London, UK, 2013.

29. ASTM C1754/C1754M. Standard Test. Method for Density and Void Content of Hardened Pervious Concrete; ASTM International: West Conshohocken, PA, USA, 2012.

30. EN 12390-5:2019. Testing Hardened Concrete. Part 5: Flexural Strength of Test. Specimens; The British Standards Institution: London, UK, 2019.

31. ASTM D2434-19. Test. Method for Permeability of Granular Soils (Constant Head); ASTM International: West Conshohocken, PA, USA, 2019.

32. ISO 354:2003. Acoustics-Measurement of Sound Absorption in a Reverberation Room; International Organization for Standardization: Geneva, Switzerland, 2003.

33. ISO 17497-1:2004. Acoustics-Sound-Scattering Properties of Surfaces. Part 1: Measurement of the Random-Incidence Scattering Coefficient in a Reverberation Room; International Organization for Standardization: Geneva, Switzerland, 2004.

34. Shtrepi, L.; Astolfi, A.; D’Antonio, G.; Vannelli, G.; Barbato, G.; Mauro, S.; Prato, A. Accuracy of the Random-Incidence Scattering Coefficient Measurement. Appl. Acoust. 2016, 106, 23-35. [CrossRef]

35. Shtrepi, L.; Prato, A. Towards a Sustainable Approach for Sound Absorption Assessment of Building Materials: Validation of Small-Scale Reverberation Room Measurements. Appl. Acoust. 2020, 165, 107304. [CrossRef]

36. ITA-Toolbox for MATLAB ${ }^{\circledR}$ v.R2018b; Developed at the Institute of Technical Acoustics at RWTH Aachen University; RWTH Aachen University: Aachen, Genmary, 2018.

37. ISO 9613-1:1993. Acoustics-Attenuation of Sound during Propagation Outdoors. Part 1: Calculation of the Absorption of Sound by the Atmosphere; International Organization for Standardization: Geneva, Switzerland, 1993.

38. Bartel, T.W. Effect of Absorber Geometry on Apparent Absorption Coefficients as Measured in a Reverberation Chamber. J. Acoust. Soc. Am. 1981, 69, 1065-1074. [CrossRef]

39. Embleton, T.F.W. Absorption Coefficients of Surfaces Calculated from Decaying Sound Fields. J. Acoust. Soc. Jpn. 1971, 50. [CrossRef]

40. Scrosati, C. Towards More Reliable Measurements of Sound Absorption Coefficient in Reverberation Rooms: An Inter-Laboratory Test. Appl. Acoust. 2020, 165, 107298. [CrossRef] 
41. ISO 11654:1997. Acoustics-Sound Absorbers for Use in Buildings-Rating of Sound Absorption; International Organization for Standardization: Geneva, Switzerland, 1997.

42. Ahmad, S.; Azad, A.K.; Loughlin, K.F. A Study of Permeability and Tortuosity of Concrete. In Proceedings of the 30th Conference on Our World in Concrete and Structures (OWICS), Singapore, 23-24 August 2005.

43. Liu, Z.; Zhan, J.; Fard, M.; Davy, J.L. Acoustic Properties of Multilayer Sound Absorbers with a 3D Printed Micro-Perforated Panel. Appl. Acoust. 2017, 121, 25-32. [CrossRef]

44. Maa, D.-Y. Microperforated-Panel Wideband Absorbers. Noise Control Eng. J. 1987, 29, 77-84. [CrossRef]

45. Kim, H.K.; Lee, H.K. Acoustic Absorption Modeling of Porous Concrete Considering the Gradation and Shape of Aggregates and Void Ratio. J. Sound Vib. 2010, 329, 866-879. [CrossRef]

46. Kephalopoulos, S.; Paviotti, M.; Anfosso-Lédée, F. Common Noise Assessment Methods in Europe (CNOSSOS-EU); Publications Office of the European Union: Luxembourg, 2012.

47. Calleri, C.; Astolfi, A.; Shtrepi, L.; Prato, A.; Schiavi, A.; Zampini, D.; Volpatti, G. Characterization of the Sound Insulation Properties of a Two-Layers Lightweight Concrete Innovative Façade. Appl. Acoust. 2019, 145, 267-277. [CrossRef]

48. Kousis, I.; Pisello, A.L. For the Mitigation of Urban Heat Island and Urban Noise Island: Two Simultaneous Sides of Urban Discomfort. Environ. Res. Lett. 2020, 15, 103004. [CrossRef] 